\title{
The gut microbiota in larvae of the housefly Musca domestica and their horizontal transfer through feeding
}

\author{
Yao Zhao ${ }^{1}$, Wanqiang Wang ${ }^{1}$, Fen Zhu ${ }^{1 *}$, Xiaoyun Wang ${ }^{1}$, Xiaoping Wang ${ }^{2}$ and Chaoliang Lei ${ }^{2}$
}

\begin{abstract}
House fly larvae provide a prolific and sustainable source of proteins used in poultry and fish feed. Wheat bran is a superior diet for house fly larvae and has been widely investigated to exploit its potential in the food and feed area. Using Illumina MiSeq 16S rDNA sequencing, this study investigated the gut microbiota of house fly larvae feeding on wheat bran and the bacterial community in the wheat bran. The bacterial communities in the house fly larvae were dominated by the phyla Proteobacteria and Firmicutes. Enterobacteriaceae and Providencia were the predominant bacteria at the family and genus levels, respectively. Some bacteria in the phyla Actinobacteria, Proteobacteria, Bacteroidetes and Firmicutes may be transferred from the gut of house flies to the wheat bran during feeding and may be involved in degrading and utilizing polysaccharides in the cell wall of wheat bran. The significance of the gut microbiota of house fly larvae, their transferring and roles in degradation of wheat bran is discussed. These findings regarding the gut microbiota of house fly larvae will provide opportunities for research on the impact of microbial communities on poultry and fish.
\end{abstract}

Keywords: Housefly, Gut microbiota, Transferring, Wheat bran

\section{Introduction}

The house fly, Musca domestica, is a cosmopolitan and synanthropic insect that serves as a vector for many human diseases (Gupta et al. 2012). However, the larvae are also resource insects with important potential applications. For instance, the larvae could be used in swine manure bioconversion and pollution control (Zhang et al. 2014). The larvae also have medicinal purposes, including beneficial effects on wounds, such as debridement (Wollina et al. 2000). The larvae also represent a sustainable and prolific source of proteins used in poultry and fish feed (Van 2013).

Because large volumes are required to supplement commercial poultry diets, the rearing technology for fly larvae requires further development. House flies can reproduce and develop in poultry and pig manure

\footnotetext{
*Correspondence: zhufen@mail.hzau.edu.cn

${ }^{1}$ Hubei International Cooperation Base for Waste Conversion by Insects,

Huazhong Agricultural University, No. 1 Shizishan Street, Hongshan

District, Wuhan 430070, China

Full list of author information is available at the end of the article
}

(Akpodiete et al. 1997; Zhu et al. 2012), but there are still a number of challenges to be addressed, including safety issues related to pathogens, heavy metals, and organic pollutants (Van 2013).

Wheat bran, the most important milling by-product of cereal grain (Prückler et al. 2014) and source of dietary fibre, minerals, vitamins and phenolic acids (Coda et al. 2013), is a superior diet for house fly larvae (Aniebo et al. 2008; Su et al. 2010). Many studies have investigated the bacterial community of adult house flies, which are considered pathogen vectors (Grübel et al. 1998; Gupta et al. 2012), but the gut microbiota in larvae and their transfer through food chain has not been characterized.

Early studies of bacterial diversity were primarily based on cultivation methods (Grübel et al. 1998; Zurek et al. 2000). However, many bacteria are uncultivable (Eilers et al. 2000). High-throughput DNA sequencing approaches provide a new means of characterizing bacterial communities and identifying cultivable and noncultivable bacteria to provide an expanded perspective on bacterial diversity with higher coverage and a focus 
on a different set of organisms (Caporaso et al. 2010; Lozupone and Knight 2006). In this study, we used Illumina MiSeq 16S rDNA sequencing to identify the microbial dynamics of the gut microbiota in house fly larvae and their food. We are interested in (1) the microbial dynamics of the gut microbiota in house fly larvae and (2) their horizontal transfer through feeding.

\section{Materials and methods}

\section{Sample collection}

The house fly colony has been reared for more than 20 years in our lab. The house fly adults were fed with milk powder and water, and the larvae were reared on moistened wheat bran [wheat bran (g):water $(\mathrm{ml})=1: 1.8]$. In this experiment, newly hatched house fly eggs were inoculated into moistened wheat bran. After 2, 24, 48, 72 and $96 \mathrm{~h}$, the house fly larvae were sampled (hereinafter referred to as Md02h, Md24h, Md48h, Md72h and Md96h). Moistened wheat bran treated with house fly larvae for $96 \mathrm{~h}$ was also sampled (hereinafter referred to as WBMd96h). As a control, moistened wheat bran not treated with house fly larvae was sampled after 24, 48, 72 and $96 \mathrm{~h}$ (hereinafter referred to as WB24h, WB48h, WB72h and WB96h). The experimental conditions were $28 \pm 1{ }^{\circ} \mathrm{C}, 80 \pm 5 \%$ relative humidity (RH), and a 13:11 h light:dark photoperiod (L:D). Three biological replicates were performed for each treatment.

\section{DNA extraction}

Prior to insect dissection, the house fly larvae were washed for 3-5 min in 70\% ethanol and rinsed three times with sterile water to remove surface contaminants. Each sample comprised three biological replicates, and each replicate contained 30 whole bodies of the 2 and 24-h larvae or 15 whole guts (from proventriculus to rectum, excluding Malpighian tubules) of the 48, 72 and 96-h larvae. The samples were then manually homogenized in extraction buffer $(20 \mathrm{mM}$ Tris- $\mathrm{HCl} \mathrm{pH} \mathrm{8.0,2} \mathrm{mM} \mathrm{sodium}$ EDTA, $1.2 \%$ Triton $^{\circledR}$ X-100 containing 20 mg lysozyme $\mathrm{ml}^{-1}$ ). The homogenates were incubated at $37^{\circ} \mathrm{C}$ for $1 \mathrm{~h}$ to extract DNA from both Gram-positive and Gram-negative bacteria. The DNA in the samples was then extracted using the TIANamp Genomic DNA Kit [TIANGEN Biotech (Beijing) LTD., China] following the manufacturer's instructions. For wheat bran, $200 \mathrm{mg}$ of each sample was used for DNA extraction with the TIANamp Stool DNA Kit [TIANGEN Biotech (Beijing) LTD., China], following the manufacturer's instructions. The quantity and quality of the DNA were measured using a NanoDrop2000 spectrophotometer (Thermo Scientific, USA). DNA samples were stored at $-80^{\circ} \mathrm{C}$ until further processing.
PCR amplification, library preparation and high-throughput sequencing

DNA was amplified using the $515 \mathrm{f} / 806 \mathrm{r}$ primer set (515f: 5'-GTG CCA GCM GCC GCG GTA A-3', 806r: 5'-XXX XXX GGA CTA CHV GGG TWT CTA AT-3'), which targets the V4 region of the bacterial 16S rDNA. The reverse primer contains a 6-bp error-correcting barcode unique to each sample. PCR amplifications were performed in a 30- $\mu \mathrm{l}$ mixture containing $15 \mu \mathrm{l}$ of Phusion High-Fidelity PCR Master Mix (New England Biolabs, UK), $0.2 \mu \mathrm{M}$ forward and reverse primers, $10 \mathrm{ng}$ of template DNA and nuclease-free water up to $30 \mu \mathrm{l}$. The PCR conditions were $98{ }^{\circ} \mathrm{C}$ for $1 \mathrm{~min}(1 \mathrm{cycle})$, then $98{ }^{\circ} \mathrm{C}$ for $10 \mathrm{~s}, 50^{\circ} \mathrm{C}$ for $30 \mathrm{~s}$ and $72{ }^{\circ} \mathrm{C}$ for $60 \mathrm{~s}$ ( 30 cycles), followed by $72{ }^{\circ} \mathrm{C}$ for $5 \mathrm{~min}$. The PCR products were verified by $2 \%$ agarose gel electrophoresis and mixed in equidense ratios. The mixture of PCR products was purified using a GeneJET Gel Extraction Kit (Thermo Scientific, USA). Sequencing libraries were generated using a NEB Next Ultra DNA Library Prep Kit for Illumina (New England Biolabs, UK). Sequencing was conducted on an Illumina MiSeq $2 \times 250$ platform at BGI, Inc. (Shenzhen, China) according to protocols described by Caporaso et al. (2012) and Kozich et al. (2013).

\section{Bioinformatics and statistical analysis}

Paired-end reads were assigned to samples based on their unique barcodes and truncated by cutting off the barcode and primer sequence. Then, the paired-end reads were merged into longer single sequences using FLASH (v1.2.11) (Magoč and Salzberg 2011). Quality filtering was performed on the raw tags under specific filtering conditions to obtain high-quality clean tags (Bokulich et al. 2013) according to the QIIME (v1.8.0) (Caporaso et al. 2010) quality-control process.

OTUs were clustered with a $97 \%$ similarity cut-off using UPARSE (v7.0.1090) (Edgar 2013). Chimeric sequences were detected and removed using UCHIME (v4.2.40) (Edgar et al. 2011). Representative sequences from each OTU were screened for further annotation. For each representative sequence, the GreenGene Database (DeSantis et al. 2006) was used with the RDP classifier (v2.2) (Wang et al. 2007) to annotate taxonomic information. Microbial diversity was analysed using QIIME v1.8.0 and displayed using R software (v3.0.3) (Caporaso et al. 2010). The alpha diversity analysis included observed species, Ace and Chao1 estimators, and the Simpson and Shannon diversity indices. The sequencing data have been submitted to the NCBI database under accession numbers SRP068683 and SRP068753. 


\section{Results}

\section{Sequencing data}

The Illumina MiSeq sequencing of the 16S rRNA gene amplicons yielded 81,523-90,132 reads of house fly larvae samples and 77,843-83,590 reads of wheat bran samples, after quality filtering and the removal of chimeric sequences (Table 1). At $97 \%$ sequence identity, the reads for the house fly samples and wheat bran samples were assigned to 145 and 231 OTUs, respectively (Additional file 1: Tables S1, S2). The rarefaction curve for every sample tended to saturation (Additional file 1: Figure S1), indicating that our sequencing results captured most of the bacterial diversity.

\section{Bacterial diversity in house fly larvae}

The bacterial communities in the house fly larvae samples were dominated by the phyla Proteobacteria and Firmicutes (Fig. 1a). The relative abundance of the phylum Actinobacteria was much higher in Md72h and Md96h samples than in the other three $M$. domestica samples (Fig. 1a). At the family level, Enterobacteriaceae was most dominant, with a relative abundance of nearly $50 \%$ (average value across all samples) (Fig. 2). Providencia dominated the bacterial communities at the genus level, with a relative abundance of $40.31 \%$ (Fig. 1b). Additionally, the Md72h and Md96h samples had generally higher Ace and Chao1 richness estimates compared with the samples Md02h, Md24h and Md48h (Table 1).

\section{Bacterial diversity in wheat bran}

The bacterial communities in the control wheat bran samples (WB24h, WB48h, WB72h and WB96h) were dominated by the phylum Proteobacteria, and its relative abundance was nearly 90\% (Fig. 1c). In the WBMd96h samples, the dominant phyla were Proteobacteria and Bacteroidetes, with relative abundances of 37.40 and $47.58 \%$, respectively (Fig. 1c). At the genus level, Myroides and Stenotrophomonas were the major taxa in the control wheat bran samples (Fig. 1d). Myroides and Sphingobacterium were the major taxa in the WBMd96h samples (Fig. 1d). The relative abundance of the genus Comamonas was much higher in the WBMd96h samples compared with the WB96h samples (Fig. 1d).

The Venn diagram of the WB96h and WBMd96h samples revealed that 78 OTUs were shared by the two samples (Fig. 3). Myroides and Acinetobacter were the major genera in these common OTUs (Fig. 1d). There were 87 unique OTUs in the WBMd96h samples (Fig. 3), and Dysgonomonas was the major genus (Fig. 1d; Additional file 1: Table S3). Moreover, the WBMd96h samples had generally higher Ace and Chao1 richness estimates than the WB96h samples (Table 1).

\section{Discussion}

To our knowledge, this study is the first to investigate the microbial dynamics of the gut microbiota in house fly larvae and their horizontal transfer through feeding. The bacterial communities in the house fly larvae samples were dominated by the phyla Proteobacteria and Firmicutes. The relative abundance of the phylum Actinobacteria was much higher in the Md72h and Md96h samples than in other house fly larvae samples. Enterobacteriaceae and Providencia were the predominant bacteria at the family and genus levels, respectively. Some bacteria in the phyla Actinobacteria, Proteobacteria, Bacteroidetes and Firmicutes were either unique to the WBMd96h samples or had much higher abundances in the WBMd96h samples compared with the WB96h samples, suggesting

Table 1 Richness and diversity estimates of the 16S rRNA gene libraries from the sequencing analysis

\begin{tabular}{|c|c|c|c|c|c|c|}
\hline Sample & Tag number ${ }^{a}$ & OTU number & Ace & Chao1 & Shannon & Simpson \\
\hline Md02h & 90132 & 83 & 96.29 & 96.57 & 1.35 & 0.30 \\
\hline$M d 24 h$ & 89186 & 68 & 81.33 & 81.33 & 0.81 & 0.56 \\
\hline Md48h & 85270 & 77 & 80.98 & 79.55 & 1.79 & 0.28 \\
\hline $\mathrm{Md} 72 \mathrm{~h}$ & 81523 & 92 & 106.81 & 113.00 & 2.33 & 0.14 \\
\hline Md96h & 82378 & 98 & 107.94 & 106.27 & 1.94 & 0.22 \\
\hline WB24h & 83590 & 85 & 130.94 & 113.88 & 2.28 & 0.13 \\
\hline WB48h & 80037 & 90 & 97.75 & 99.17 & 2.50 & 0.12 \\
\hline WB72h & 80319 & 112 & 115.05 & 113.50 & 2.69 & 0.09 \\
\hline WB96h & 77843 & 116 & 123.94 & 121.63 & 2.91 & 0.09 \\
\hline WBMd96h & 80089 & 165 & 170.33 & 167.50 & 3.08 & 0.07 \\
\hline
\end{tabular}

MD02h, MD24h, MD48h, MD72h and MD96h refer to Musca domestica larvae reared on moistened wheat bran for 2, 24, 48, 72 and 96 h. WB24h, WB48h, WB72h and WB96h refer to moistened wheat bran not treated with house fly larvae after 24, 48, 72 and $96 \mathrm{~h}$. WBMd96h refers to moistened wheat bran treated with house fly larvae for $96 \mathrm{~h}$. Each treatment included three biological replicates

a Tag number after quality filtering and removal of chimeric sequences

b Operational taxonomic units (OTUs) were defined by pairwise $97 \%$ sequence identity 

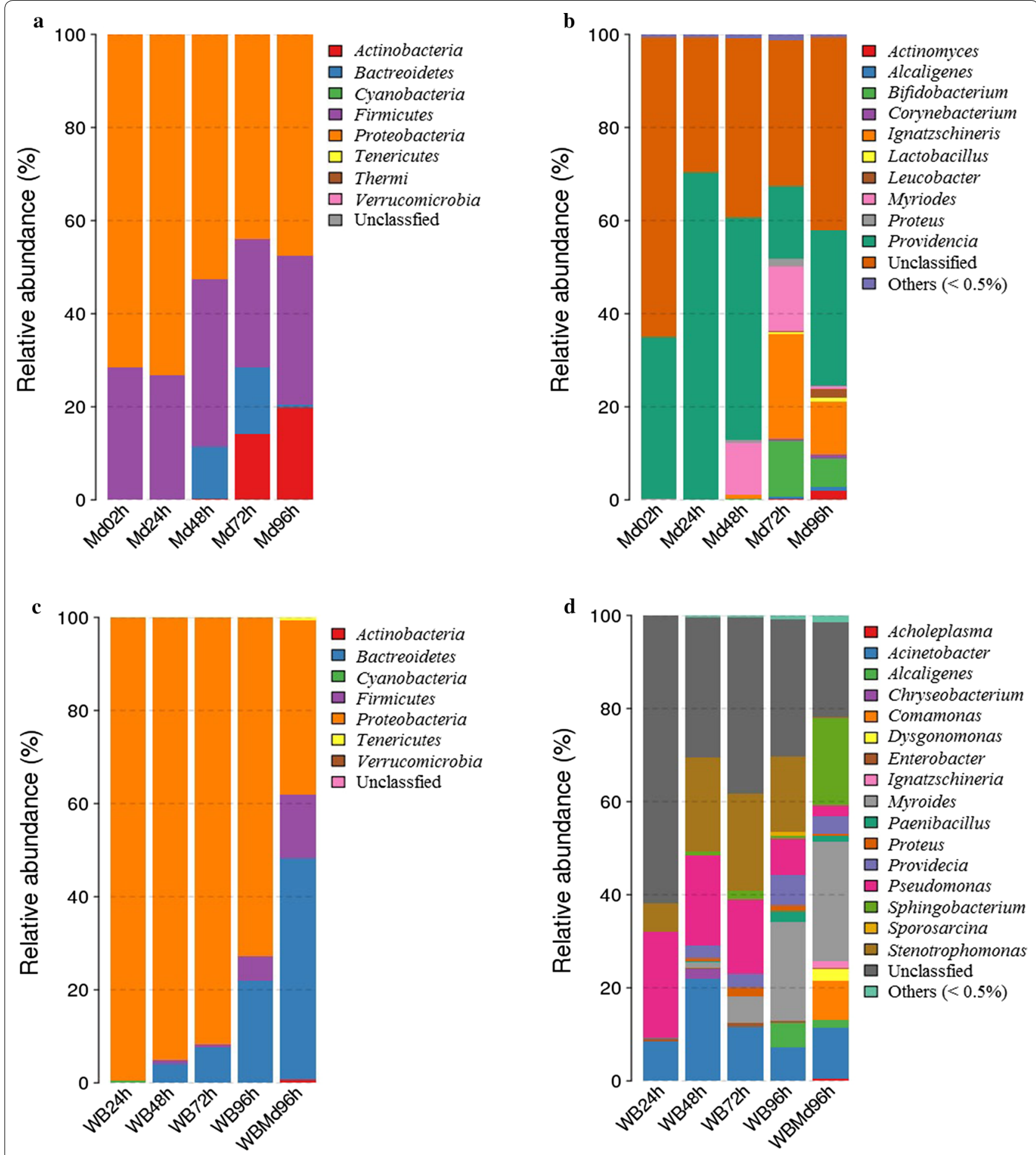

Fig. 1 Relative abundances of bacteria at the phylum and genus levels in samples of Musca domestica larvae and wheat bran. a Relative abundances of bacteria at the phylum level in M. domestica larvae. b Relative abundances of bacteria at the genus level in M. domestica larvae. c Relative abundances of bacteria at the phylum level in wheat bran. d Relative abundances of bacteria at the genus level in wheat bran. MD02h, MD24h, MD48h, MD72h and MD96h refer to Musca domestica larvae reared on moistened wheat bran for 2, 24, 48, 72 and $96 \mathrm{~h}$. WB24h, WB48h, WB72h and WB96h refer to moistened wheat bran not treated with house fly larvae after 24, 48, 72 and $96 \mathrm{~h}$. WBMd96h refers to moistened wheat bran treated with house fly larvae for $96 \mathrm{~h}$. Each treatment included three biological replicates 


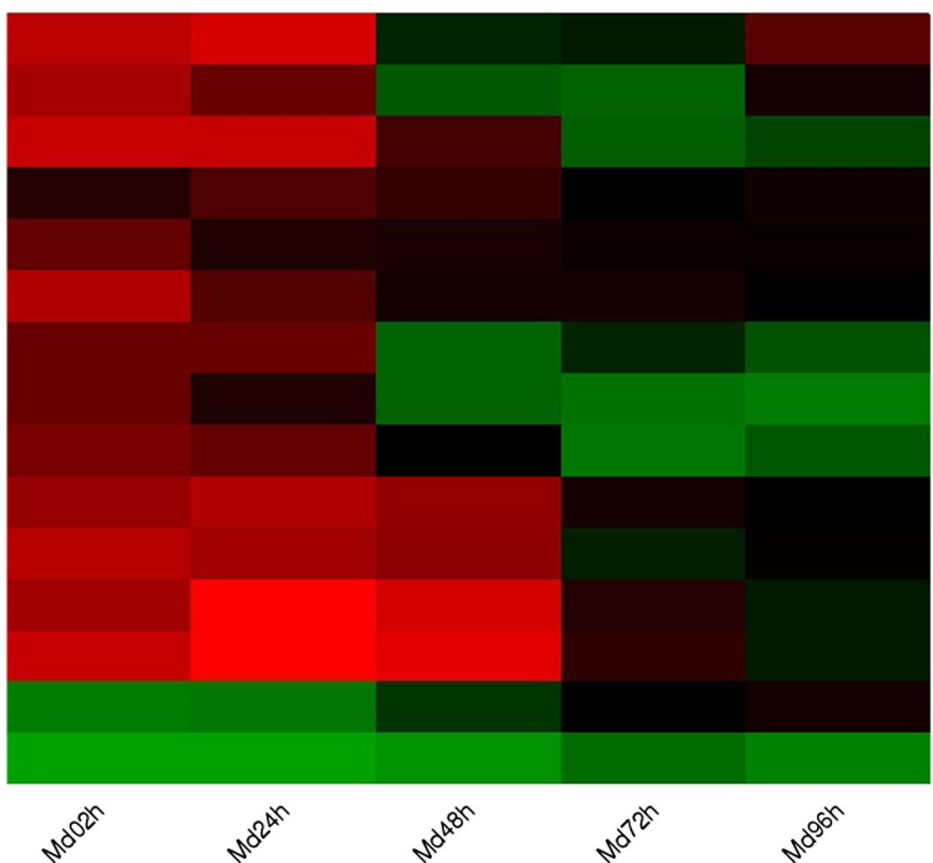

Planococcaceae

Flavobacteriaceae Bifidobacteriaceae Others $(<0.5 \%)$ Lactobacillaceae Alcaligenaceae Unclassified Enterococcaceae Xanthomonadaceae Corynebacteriaceae Comamonadaceae Microbacteriaceae Actinomycetaceae Leuconostocaceae Enterbacteriaceae

\section{Relative Abundance}

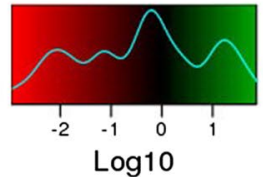

Fig. 2 Heat maps of the relative abundances and distributions of bacterial families in Musca domestica larvae. The colour code indicates relative abundance, ranging from red (low abundance) to black to green (high abundance). Each treatment included three biological replicates. To minimize the degree of difference in relative abundance values, all values were log transformed

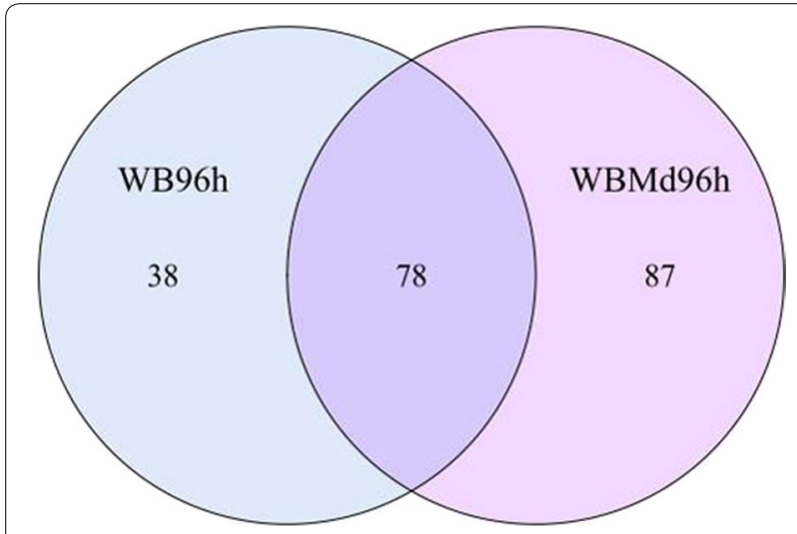

Fig. 3 Venn diagram of WB96h and WBMd96h samples at distance 0.03. The numbers represent the number of unique OTUs in each sample and common OTUs shared by the two samples. WB96h refers to the moistened wheat bran not treated with house fly larvae after $96 \mathrm{~h}$. WBMd96h refers to the moistened wheat bran treated with house fly larvae for $96 \mathrm{~h}$. Each treatment included three biological replicates

that they might have been transferred from the gut of the house fly to the wheat bran during feeding and might be involved in degrading and utilizing polysaccharides in the cell walls of wheat bran.

The bacterial communities in the guts of house fly larvae were dominated by the phylum Proteobacteria and primarily the class Gammaproteobacteria (Additional file 1: Table S1). Gammaproteobacteria are also commonly present in the guts of many other insects, such as the fruit fly Drosophila melanogaster (Corbyharris et al. 2007), the mosquito Culex quinquefasciatus (Pidiyar et al. 2004), the pea aphid Acyrthosiphon pisum (Oliver et al. 2010), the honeybee Apis mellifera (Jeyaprakash et al. 2003) and the gypsy moth Lymantria dispar (Broderick et al. 2004). Within Proteobacteria, members of the family Enterobacteriaceae dominated the bacterial communities, consistent with previous findings in the gut of house flies (Gupta et al. 2012). Enterobacteriaceae is also dominant in the gut of the flesh fly (Gupta et al. 2014) and some fruit fly species (Aharon et al. 2013; Behar et al. 2008; Wang et al. 2014). Enterobacteriaceae is a type of diazotrophic bacteria, which can help insects fix nitrogen (Dixon and Kahn 2004). Moreover, it has been reported that the Enterobacteriaceae community in the gut of medfly may indirectly contribute to host fitness by preventing the establishment or proliferation of pathogenic bacteria (Dillon and Dillon 2004).

Firmicutes was also a major component in the gut of house fly larvae. Staphylococcus belongs to this phylum (Additional file 1: Table S1) and has been frequently detected in other studies on house flies (Grübel et al. 1998; Gupta et al. 2012; Zurek et al. 2000). In the present study, Actinobacteria was another major phylum in the 
Md72h and Md96h samples, and the relative abundance of Actinobacteria was much higher in the WBMd96h than the WB96h samples. This result suggests that Actinobacteria transferred to the wheat bran when the house fly larvae were feeding. Actinobacteria associated with termites facilitate nutrient acquisition from diverse polysaccharides, including cellulose (Pasti and Belli 1985; Watanabe et al. 2003) and hemicelluloses (Schäfer et al. 1996), and Actinobacteria may similarly facilitate the utilization of polysaccharides in wheat bran by house flies. Arabinoxylans and $\beta$-glucans are polysaccharides in the cell wall of wheat bran and have a potential role in lowering the risk of type II diabetes, colorectal cancer and cardiovascular and diverticular diseases (Poutanen et al. 2014). Actinobacteria has also been reported to exhibit diverse physiological and metabolic properties, such as the production of extracellular enzymes and the formation of a wide variety of secondary metabolites (Schrempf 2001).

Although the gut microbiota of house flies growing in different habitats and on different diets vary, Providencia and Proteus are always present within the gut of house flies. For example, species of Providencia and Proteus were detected in the guts of laboratory-reared newly emerged adults (Su et al. 2010). Bacteria collected from adult house flies in public places also included the genera Providencia and Proteus (Gupta et al. 2012). Zurek et al. isolated Providencia rettgeri and Providencia stuartii from the intestinal tracts of house fly larvae collected from corn silage and turkey bedding (Zurek et al. 2000). In addition, Grubel et al. reported several bacterial species from the digestive tracts of laboratory-reared adult house flies, including Providencia (Grübel et al. 1998).

Providencia and Proteus were also detected in house fly larvae samples in the present study. Providencia is a genus of ubiquitous Gram-negative bacteria in the family Enterobacteriaceae and cause several human diseases (Gupta et al. 2012). Providencia have been identified as part of the normal human gut flora, and the genomes of some strains have been sequenced as part of the Human Microbiome Project (Stefano 2009). In addition, Providencia has been associated with numerous animals, including penguin (Muller 1983), sea turtles (Foti et al. 2009), shark (Interaminense et al. 2010), nematodes (Jackson et al. 1995) and snakes (Jho et al. 2011). Providencia strains have also been observed in association with various species of fly such as blowflies (Ahmad et al. 2006), stable flies (Mramba et al. 2006) and fruit flies (Aharon et al. 2013; Chandler et al. 2011; Corbyharris et al. 2007). For instance, Providencia strains have been isolated as infectious agents with varied virulence towards D. melanogaster ((Galac and Lazzaro 2011; Juneja and Lazzaro 2009). Additionally, some specific strains of Providencia can metabolize rhamnose (Galac and Lazzaro 2012). Proteus has been reported to protect the host from invasion by pathogenic microorganisms (Erdmann 1987; Greenberg and Klowden 1973). Greenberg and Klowden demonstrated that Proteus mirabilis is maintained at high levels in the gut of house fly larvae while suppressing the growth of two pathogenic microorganisms, Salmonella typhimurium and Pseudomonas aeruginosa (Greenberg and Klowden 1973). Erdmann determined that aromatic metabolites of $P$. mirabilis are involved in the suppression of pathogens in calliphorid larvae (Erdmann 1987). P. mirabilis from the salivary glands of the blow fly Lucilia sericata swarm significantly and produce a strong odour that attracts additional blow flies (Ma et al. 2012). We speculate that the genus Proteus may produce volatiles that serve as an oviposition attractant for the house fly.

It is well known that endosymbionts can confer ecologically relevant traits to their host. Symbiotic bacteria contributed to fitness of olive flies Bactrocera oleae (BenYosef et al. 2010), and enable B. oleae to exploit intractable sources of nitrogen and overcome host defences (Ben-Yosef et al. 2014, 2015; Pavlidi et al. 2017). Endosymbionts could improve sterile male performance in Mediterranean fruit fly Ceratitis capitata (Yuval et al. 2013). In addition, substrate bacteria is also essential for larval survival and development (Zurek et al. 2000). The larvae of the stable fly Stomoxys calcitrans fail to develop on egg yolk medium not inoculated with bacteria but complete development on medium inoculated with Acinetobacter sp., Empedobacter breve and Flavobacterium odoratum, confirming that bacteria are required to complete development (Lysyk et al. 1999). The genera Bacillus, Enterobacter and Myroides were detected in our wheat bran samples (Additional file 1: Table S2), and specific species of these genera contribute to the development of M. domestica larvae (Su et al. 2010).

Apart from the bacteria in the phylum Actinobacteria discussed above, several other phyla were observed that might be involved in degrading and utilizing polysaccharides in the cell wall of wheat bran, such as Proteobacteria, Bacteroidetes and Firmicutes, including the family Sphingobacteriaceae and the genera Comamonas, Dysgonomonas, Bacteroides, Lysinibacillus and Lactobacillus. Compared with the WB96h samples, these bacteria were either unique to the WBMd96h samples or had much higher abundances in the WBMd96h samples, suggesting that these bacteria were transferred from the gut of the house fly to the wheat bran during feeding. Species of the family Sphingobacteriaceae are capable of degrading pectin, xylan, laminarin and other polysaccharides (Pankratov et al. 2007). The genus Comamonas can be used in the utilization and bioconversion of lignin (Chen et al. 
2012). Furthermore, a microbial community including the genera Dysgonomonas, Bacteroides and Lysinibacillus expressed alkaliphilic xylanase, which may have potential implications in the pulp and paper industries ( $\mathrm{Lv}$ et al. 2008). In addition, bioprocessing by Lactobacillus, yeast and cell-wall-degrading enzymes strongly increases the digestibility of proteins and phytase activity in wheat bran (Arte et al. 2015). The genera Comamonas, Dysgonomonas and Bacteroides were also detected in wildcollected house flies (Gupta et al. 2012; Wei et al. 2013), suggesting these genera may widely exist in the house fly. Further detailed studies of the bacteria identified in the present study may reveal potential applications in wheat bran processing and many other related areas.

Several other genera reported in the house fly (Grübel et al. 1998; Gupta et al. 2012; Zurek et al. 2000), such as Serratia and Morganella, were not detected in our study. This discrepancy may be attributable to differences in habitat, diet, life stage, etc. The bacterial diversity associated with Anopheles gambiae varies depending on the habitat of the mosquito (Wang et al. 2011). Bacterial abundances and distribution were found different between laboratory-reared flies and wild-collected flies (Aharon et al. 2013). Gut microbial communities and dominant taxa vary as a result of the influence of larval diet and nutrition (Broderick et al. 2004; Chandler et al. 2011). In addition, the diversity of bacteria occupying Bactrocera dorsalis vary across different life stages of the fly (Andongma et al. 2015). The sterilizing irradiation affected the gut bacterial community structure of the Mediterranean fruit fly C. capitata (Ami et al. 2010). House fly larvae may be a sustainable protein source, and the gut microbiota of these larvae represents an intriguing area of study for microbial ecology that will provide opportunities for research on the impact of microbial communities on poultry and fish. The findings presented here will also facilitate the elucidation of the roles of these bacteria in degrading and utilizing polysaccharides in the cell wall of wheat bran. Innovative and simple transformation processes will be critical to exploiting the nutritional quality of wheat bran and will also be applicable to industrial production.

\section{Additional file}

Additional file 1. Additional figure and tables.

\section{Authors' contributions}

$Y Z, W Q W, F Z$ designed the experiment. YZ and WQW did the experiment and analysed the results. YZ and FZ wrote the paper. XPW and CLL revised the paper. All authors read and approved the final manuscript.

\begin{abstract}
Author details
${ }^{1}$ Hubei International Cooperation Base for Waste Conversion by Insects, Huazhong Agricultural University, No. 1 Shizishan Street, Hongshan District, Wuhan 430070, China. ${ }^{2}$ Hubei Insect Resources Utilization and Sustainable Pest Management Key Laboratory, Huazhong Agricultural University, Wuhan 430070, China.
\end{abstract}

\section{Acknowledgements}

We would like to thank the technical support from BGI Inc. (Shenzhen, China) for their assistance in bioinformatics analysis.

\section{Competing interests}

The authors declare that they have no competing interests.

\section{Availability of data and materials}

The sequencing data have been submitted to the NCBI database under Accession Numbers SRP068683 and SRP068753.

\section{Funding}

This study was funded by the European Seventh Framework Programme (Grant Number 034082) and the Fundamental Research Funds for the Central Universities (Grant Number 2014PY059).

\section{Publisher's Note}

Springer Nature remains neutral with regard to jurisdictional claims in published maps and institutional affiliations.

Received: 1 March 2017 Accepted: 22 June 2017

Published online: 10 July 2017

\section{References}

Aharon Y, Pasternak Z, Yosef MB, Behar A, Lauzon C, Yuval B, Jurkevitch E (2013) Phylogenetic, metabolic, and taxonomic diversities shape Mediterranean fruit fly microbiotas during ontogeny. Appl Environ Microbiol 79(1):303-313

Ahmad A, Broce A, Zurek L (2006) Evaluation of significance of bacteria in larval development of Cochliomyia macellaria (Diptera: calliphoridae). J Med Entomol 43:1129-1133

Akpodiete O, Ologhobo A, Oluyemi J (1997) Production and nutritive value of housefly maggot meal on three substrates of poultry faeces. J Appl Anim Res 12:101-106

Ami EB, Yuval B, Jurkevitch E (2010) Manipulation of the microbiota of massreared Mediterranean fruit flies Ceratitis capitata (Diptera: Tephritidae) improves sterile male sexual performance. ISME J 4(1):28-37

Andongma AA, Wan L, Dong YC, Li P, Desneux N, White JA, Niu CY (2015) Pyrosequencing reveals a shift in symbiotic bacteria populations across life stages of Bactrocera dorsalis. Sci Rep 5:9470

Aniebo A, Erondu E, Owen O (2008) Proximate composition of housefly larvae (Musca domestica) meal generated from mixture of cattle blood and wheat bran. Livest Res Rural Dev 20:1-5

Arte E, Rizzello CG, Verni M, Nordlund E, Katina K, Coda R (2015) Impact of enzymatic and microbial bioprocessing on protein modification and nutritional properties of wheat bran. J Agric Food Chem 63:1-14

Behar A, Yuval B, Jurkevitch E (2008) Gut bacterial communities in the Mediterranean fruit fly (Ceratitis capitata) and their impact on host longevity. J Insect Physiol 54:1377-1383

Ben-Yosef M, Aharon Y, Jurkevitch E, Yuval B (2010) Give us the tools and we will do the job: symbiotic bacteria affect olive fly fitness in a diet-dependent fashion. Proc R Soc Lond B Biol Sci 277(1687):1545-1552

Ben-Yosef M, Pasternak Z, Jurkevitch E, Yuval B (2014) Symbiotic bacteria enable olive flies (Bactrocera oleae) to exploit intractable sources of nitrogen. J Evol Biol 27(12):2695-2705

Ben-Yosef M, Pasternak Z, Jurkevitch E, Yuval B (2015) Symbiotic bacteria enable olive fly larvae to overcome host defences. R Soc Open Sci 2(7):150170 
Bokulich NA, Subramanian S, Faith JJ, Gevers D, Gordon JI, Knight R, Mills DA, Caporaso JG (2013) Quality-filtering vastly improves diversity estimates from Illumina amplicon sequencing. Nat Methods 10:57-59

Broderick NA, Raffa KF, Goodman RM, Handelsman J (2004) Census of the bacterial community of the gypsy moth larval midgut by using culturing and culture-independent methods. Appl Environ Microbiol 70:293-300

Caporaso JG, Kuczynski J, Stombaugh J, Bittinger K, Bushman FD, Costello EK, Fierer N, Peña AG, Goodrich JK, Gordon JI (2010) QIIME allows analysis of high-throughput community sequencing data. Nat Methods 7:335-336

Caporaso JG, Lauber CL, Walters WA, Berg-Lyons D, Huntley J, Fierer N, Owens SM, Betley J, Fraser L, Bauer M, Gormley N, Gilbert JA, Smith G, Knight $R$ (2012) Ultra-high-throughput microbial community analysis on the Illumina HiSeq and MiSeq platforms. ISME J 6:1621-1624

Chandler JA, Lang JM, Bhatnagar S, Eisen JA, Kopp A (2011) Bacterial communities of diverse Drosophila species: ecological context of a host-microbe model system. PLoS Genet 7:e1002272

Chen Y, Chai L, Zhu Y, Yang Z, Zheng Y, Zhang H (2012) Biodegradation of kraft lignin by a bacterial strain Comamonas sp. B-9 isolated from eroded bamboo slips. J Appl Bacteriol 112:900-906

Coda R, Rizzello CG, Curiel JA, Poutanen K, Katina K (2013) Effect of bioprocessing and particle size on the nutritional properties of wheat bran fractions. Innov Food Sci Emerg 25:19-27

Corbyharris V, Pontaroli AC, Shimkets LJ, Bennetzen JL, Habel KE, Promislow DE (2007) Geographical distribution and diversity of bacteria associated with natural populations of Drosophila melanogaster. Appl Environ Microbiol 73:3470-3479

DeSantis TZ, Hugenholtz P, Larsen N, Rojas M, Brodie EL, Keller K, Huber T, Dalevi D, Hu P, Andersen GL (2006) Greengenes, a chimera-checked $16 \mathrm{~S}$ rRNA gene database and workbench compatible with ARB. Appl Environ Microb 72:5069-5072

Dillon RJ, Dillon VM (2004) The gut bacteria of insects: nonpathogenic interactions. Annu Rev Entomol 49:71-92

Dixon R, Kahn D (2004) Genetic regulation of biological nitrogen fixation. Nat Rev Microbiol 2:621-631

Edgar RC (2013) UPARSE: highly accurate OTU sequences from microbial amplicon reads. Nat Methods 10:996-998

Edgar RC, Haas BJ, Clemente JC, Quince C, Knight R (2011) UCHIME improves sensitivity and speed of chimera detection. Bioinformatics 27:2194-2200

Eilers H, Pernthaler J, Glöckner FO, Amann R (2000) Culturability and in situ abundance of pelagic bacteria from the North Sea. Appl Environ Microbiol 66:3044-3051

Erdmann GR (1987) Antibacterial action of myiasis-causing flies. Parasitol Today 3(7):214-216

Foti M, Giacopello C, Bottari T, Fisichella V, Rinaldo D, Mammina C (2009) Antibiotic resistance of Gram Negatives isolates from loggerhead sea turtles (Caretta caretta) in the central Mediterranean Sea. Mar Pollut Bull 58:1363-1366

Galac MR, Lazzaro BP (2011) Comparative pathology of bacteria in the genus Providencia to a natural host, Drosophila melanogaster. Microbes Infect 13:673-683

Galac MR, Lazzaro BP (2012) Comparative genomics of bacteria in the genus Providencia isolated from wild Drosophila melanogaster. BMC Genom 13:612

Greenberg B, Klowden M (1973) Enteric bacterial interactions in insects. Am J Clin Nutr 25:1459-1466

Grübel P, Hoffman JS, Chong FK, Burstein NA, Mepani C, Cave DR (1998) Vector potential of houseflies (Musca domestica) for Helicobacter pylori. J Clin Microbiol 35:1300-1303

Gupta AK, Nayduch D, Verma P, Shah B, Ghate HV, Patole MS, Shouche YS (2012) Phylogenetic characterization of bacteria in the gut of house flies (Musca domestica L.). FEMS Microbiol Ecol 79:581-593

Gupta AK, Rastogi G, Nayduch D, Sawant SS, Bhonde RR, Shouche YS (2014) Molecular phylogenetic profiling of gut-associated bacteria in larvae and adults of flesh flies. Med Vet Entomol 28:345-354

Interaminense JA, Nascimento DC, Ventura RF, Batista JE, Souza MM, Hazin FH, Pontesfilho NT, Limafilho JV (2010) Recovery and screening for antibiotic susceptibility of potential bacterial pathogens from the oral cavity of shark species involved in attacks on humans in Recife, Brazil. J Med Entomol 59:941-947

Jackson TJ, Wang H, Nugent MJ, Griffin CT, Burnell AM, Dowds BCA (1995) Isolation of insect pathogenic bacteria, Providencia rettgeri, from Heterorhabditis spp. J Appl Microbiol 78:237-244
Jeyaprakash A, Hoy MA, Allsopp MH (2003) Bacterial diversity in worker adults of Apis mellifera capensis and Apis mellifera scutellata (Insecta: Hymenoptera) assessed using 16S rRNA sequences. J Invertebr Pathol 84:96-103

Jho YS, Park DH, Lee JH, Cha SY, Han JS (2011) Identification of bacteria from the oral cavity and cloaca of snakes imported from Vietnam. Lab Anim Res 27:213-217

Juneja P, Lazzaro BP (2009) Providencia sneebia sp. nov. and Providencia burhodogranariea sp. nov., isolated from wild Drosophila melanogaster. Int I Syst Evol Microbiol 59:1108-1111

Kozich JJ, Westcott SL, Baxter NT, Highlander SK, Schloss PD (2013) Development of a dual-index sequencing strategy and curation pipeline for analyzing amplicon sequence data on the MiSeq Illumina sequencing platform. Appl Environ Microb 79:5112-5120

Lozupone C, Knight R (2006) UniFrac: a new phylogenetic method for comparing microbial communities. Appl Environ Microbiol 71:8228-8235

Lv Z, Yang J, Yuan H (2008) Production, purification and characterization of an alkaliphilic endo- $\beta-1,4-x y l a n a s e$ from a microbial community EMSD5. Enzyme Microb Technol 43:343-348

LysykTJ, Kalischuk-Tymensen L, Selinger LB, Lancaster RC, Wever L, Cheng KJ (1999) Rearing stable fly larvae (Diptera: Muscidae) on an egg yolk medium. J Med Entomol 36:382-388

Ma Q, Fonseca A, Liu W, Fields AT, Pimsler ML, Spindola AF, Tarone AM, Crippen TL, Tomberlin JK, Wood TK (2012) Proteus mirabilis interkingdom swarming signals attract blow flies. ISME J 6:1356-1366

Magoč T, Salzberg SL (2011) FLASH: fast length adjustment of short reads to improve genome assemblies. Bioinformatics 27:2957-2963

Mramba F, Broce A, Zurek L (2006) Isolation of Enterobacter sakazakii from stable flies, Stomoxys calcitrans L. (Diptera: Muscidae). J Food Prot 69:671-673

Muller HE (1983) Providencia friedericiana, a new species isolated from penguins. Int J Syst Bacteriol 33:709-715

Oliver KM, Degnan PH, Burke GR, Moran NA (2010) Facultative symbionts in aphids and the horizontal transfer of ecologically important traits. Annu Rev Entomol 55:247-266

Pankratov TA, Tindall BJ, Liesack W, Dedysh SN (2007) Mucilaginibacter paludis gen. nov., sp. nov. and Mucilaginibacter gracilis sp. nov., pectin-, xylan- and laminarin-degrading members of the family Sphingobacteriaceae from acidic Sphagnum peat bog. Int J Syst Evol Microbiol 57:2349-2354

Pasti MB, Belli ML (1985) Cellulolytic activity of Actinomycetes isolated from termites (Termitidae) gut. FEMS Microbiol Lett 26:107-112

Pavlidi N, Gioti A, Wybouw N, Dermauw W, Ben-Yosef M, Yuval B, Jurkevich E, Kampouraki A, Van Leeuwen T, Vontas J (2017) Transcriptomic responses of the olive fruit fly Bactrocera oleae and its symbiont Candidatus Erwinia dacicola to olive feeding. Sci Rep 7:42633

Pidiyar VJ, Jangid K, Patole MS, Shouche YS (2004) Studies on cultured and uncultured microbiota of wild Culex quinquefasciatus mosquito midgut based on $16 \mathrm{~s}$ ribosomal RNA gene analysis. Am J Trop Med Hyg 70:597-603

Poutanen K, Sozer N, Valle GD (2014) How can technology help to deliver more of grain in cereal foods for a healthy diet? J Cereal Sci 59:327-336

Prückler M, Siebenhandl-Ehn S, Apprich S, Höltinger S, Haas C, Schmid E, Kneifel W (2014) Wheat bran-based biorefinery 1: composition of wheat bran and strategies of functionalization. LWT-Food Sci Technol $56: 211-221$

Schäfer A, Konrad R, Kuhnigk T, Kämpfer P, Hertel H, König H (1996) Hemicellulose-degrading bacteria and yeasts from the termite gut. J Appl Microbiol 80:471-478

Schrempf H (2001) Recognition and degradation of chitin by streptomycetes. Antonie Van Leeuwenhoek 79:285-289

Stefano VD (2009) The NIH human microbiome project. Genome Res 19:2317-2323

Su Z, Zhang M, Liu X, Tong L, Huang Y, Li G, Pang Y (2010) Comparison of bacterial diversity in wheat bran and in the gut of larvae and newly emerged adult of Musca domestica (Diptera: Muscidae) by use of ethidium monoazide reveals bacterial colonization. J Econ Entomol 103:1832-1841

Van HA (2013) Potential of insects as food and feed in assuring food security. Annu Rev Entomol 58:563-583

Wang Q, Garrity GM, Tiedje JM, Cole JR (2007) Naive Bayesian classifier for rapid assignment of rRNA sequences into the new bacterial taxonomy. Appl Environ Microb 73:5261-5267 
Wang Y, lii TMG, Kukutla P, Yan G, Xu J (2011) Dynamic gut microbiome across life history of the malaria mosquito Anopheles gambiae in Kenya. PLoS ONE 6:e24767

Wang A, Yao Z, Zheng W, Zhang H (2014) Bacterial communities in the gut and reproductive organs of Bactrocera minax (Diptera: Tephritidae) based on 454 pyrosequencing. PLoS ONE 9:e106988

Watanabe Y, Shinzato N, Fukatsu T (2003) Isolation of Actinomycetes from termites' guts. Biosci Biotechnol Biochem 67:1797-1801

Wei T, Hu J, Miyanaga K, Tanji Y (2013) Comparative analysis of bacterial community and antibiotic-resistant strains in different developmental stages of the housefly (Musca domestica). Appl Microbiol Biotechnol 97(4):1775-1783

Wollina U, Karte K, Herold C, Looks A (2000) Biosurgery in wound healing - the renaissance of maggot therapy. J Eur Acad Dermatol 14:285-289
Yuval B, Ben-Ami E, Behar A, Ben-Yosef M, Jurkevitch E (2013) The Mediterranean fruit fly and its bacteria-potential for improving sterile insect technique operations. J Appl Entomol 137(s1):39-42

Zhang ZJ, Shen JG, Wang H, Liu M, Wu LH, Fan P, He Q, Li HY, Zheng CF, Xu XH (2014) Attenuation of veterinary antibiotics in full-scale vermicomposting of swine manure via the housefly larvae (Musca domestica). Sci Rep 4:87-92

Zhu FX, Wang WP, Hong CL, Feng MG, Xue ZY, Chen XY, Yao YL, Yu M (2012) Rapid production of maggots as feed supplement and organic fertilizer by the two-stage composting of pig manure. Bioresour Technol 116:485-491

Zurek L, Schal C, Watson DW (2000) Diversity and contribution of the intestinal bacterial community to the development of Musca domestica (Diptera: Muscidae) larvae. J Med Entomol 37:924-928

\section{Submit your manuscript to a SpringerOpen ${ }^{\circ}$ journal and benefit from:}

- Convenient online submission

- Rigorous peer review

- Open access: articles freely available online

- High visibility within the field

- Retaining the copyright to your article

Submit your next manuscript at $\boldsymbol{\nabla}$ springeropen.com 